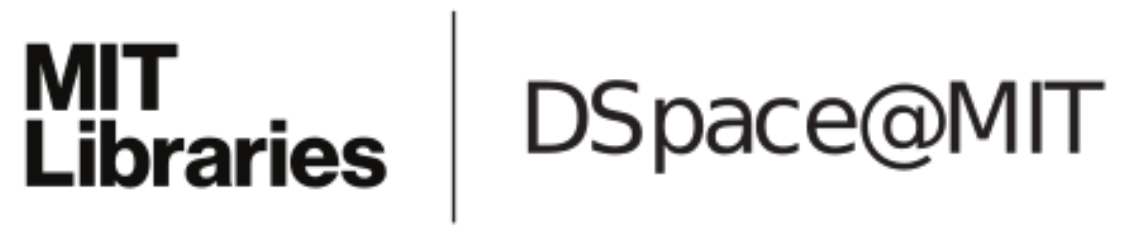

\author{
MIT Open Access Articles
}

Impacts of personality traits on consumer innovation success

The MIT Faculty has made this article openly available. Please share how this access benefits you. Your story matters.

Citation: Stock, Ruth Maria et al. "Impacts of personality traits on consumer innovation success." Research Policy 45, 4 (May 2016): 757-769 (c) 2015 Elsevier B.V.

As Published: http://dx.doi.org/10.1016/j.respol.2015.12.002

Publisher: Elsevier BV

Persistent URL: https://hdl.handle.net/1721.1/123986

Version: Author's final manuscript: final author's manuscript post peer review, without publisher's formatting or copy editing

Terms of use: Creative Commons Attribution-NonCommercial-NoDerivs License 
Ruth Maria Stock, Ph.D. (Corresponding author)

Professor of Marketing and Human Resource Management

Technische Universität Darmstadt

Hochschulstr. 1

64287 Darmstadt

Germany

Phone: (+49-6151)16-7322

Fax: (+49-6151)16-7320

E-mail: rsh@stock-homburg.de

Eric von Hippel, Ph.D.

Professor of Management of Innovation

MIT Sloan School of Management

50 Memorial Drive

Cambridge, Massachusetts 02142

United States

Phone: (617) 253-7155

Fax: (617) 253-2660

E-mail: evhippel@mit.edu

Lennart N. Gillert

Ph.D. Candidate

Technische Universität Darmstadt

Hochschulstr. 1

64287 Darmstadt

Germany

Phone: (+49-6151)16-76793

Fax: (+49-6151)16-7320

E-mail: lennart.schnarr@stock-homburg.de 


\title{
Impacts of Personality Traits on Consumer Innovation Success
}

\begin{abstract}
Via a study of innovating German consumers, we explore links between the "Big Five" personality traits and successful accomplishment of three basic innovation process stages by consumer-innovators: (1) generating an idea for a new product or product improvement, (2) developing a prototype that implements that idea, and (3) diffusing the innovation to others. We find that personality traits significantly associated with success differ at each stage. First, those who score higher on openness to experience are significantly more likely to have new product ideas. Second, being introverted and conscientious is significantly associated with successful prototyping. Third, those who possess high levels of conscientiousness are more likely to successfully commercially diffuse their innovations, whereas, in contrast, conscientiousness lowers the likelihood of successful peer-to-peer diffusion.
\end{abstract}

Since the personality traits associated with successful completion of each stage differ, and the same individual with the same traits must traverse each stage in sequence, we find that personality traits strongly affect the likelihood of overall success. That is, an individual innovator with a personality profile highly favorable to successful completion of all stages is several times more likely to successfully complete all three stages than is an individual with a highly unfavorable profile. We suggest solutions to this practical problem, and also offer suggestions for further research.

Keywords: consumer innovation, personality, diffusion, product solution 


\section{Introduction and overview}

Product development by consumers has been shown to be large in both scale and scope. Thus, representative national surveys of consumers in six countries have shown that each year tens of millions of consumers spend tens of billions of dollars developing and improving consumer products for their own use (de Jong 2013; de Jong et al. 2015; Kim 2015; von Hippel, de Jong, and Flowers 2012; von Hippel, Ogawa, and de Jong, 2011). Consumer innovation has also been found to provide significant economic benefits to national economies. Specifically, many consumer-developed innovations diffuse widely via peer-topeer and/or market channels (de Jong et al. 2015; Ogawa and Piller 2006; von Hippel, de Jong, and Flowers 2012). The net effect is an increase in social welfare (Gambardella, Raasch, and von Hippel 2015).

Given the scale and importance of innovation by consumers, it is clearly important to improve our understanding of the phenomenon, and to learn how it may be done better or more broadly. In this regard, a striking finding of the previously mentioned national surveys is that the fraction of consumers engaging in product development is relatively small, ranging from $1.5 \%$ (South Korea) to $6.1 \%$ (UK) of national populations in the six countries studied to date. Further, only about $12 \%$ of those who do innovate go on to diffuse their innovation, either peer-to-peer or commercially (de Jong et al. 2015; von Hippel, de Jong, and Flowers 2012; von Hippel, Ogawa, and de Jong 2011). It therefore becomes important to understand whether there are differences between consumer-innovators who succeed at innovationrelated tasks and those who fail.

To date, prior research has identified a number of factors to be significantly associated with successful realization of consumer innovation projects such as demographics (e.g., Ogawa and Pongtagalert 2013; von Hippel, de Jong, and Flowers 2012) or motives (e.g., Stock, Oliveira, and von Hippel 2015), but has not explored the impact of personality traits as enduring and fundamental predictors of individual behavior. In this paper, in a first-of-type study, we utilize a questionnaire survey of 547 German consumers to explore links between the "Big Five" personality traits and the successful completion of each of three basic innovation process stages: (1) generating an idea for a new product or product improvement; (2) developing a prototype that implements that idea; (3) diffusing the innovation to others. Our major findings are, first, that Big Five personality traits do indeed significantly affect the likelihood of successful accomplishment of each of the three basic innovation process stages by consumers developing innovations for their own use. Second, we find that traits associated with success differ across those three phases. Third, we find that the impact of personality 
traits on individuals' success in traversing all three stages is high. An individual innovator with a personality profile highly favorable to successful completion of all stages is several times more likely to successfully complete all three stages than is an individual with a highly unfavorable profile.

In a discussion section, we note that, since the Big Five personality traits are hardly malleable within individuals, other solutions to the significant impact of personality traits on consumer innovation and diffusion success must be considered. One approach we suggest is to shift from today's dominant pattern of all innovation process steps being carried out by a single consumer, to a collaborative mode involving multiple individuals. These individuals may then collectively have all the personality traits needed to successfully accomplish all stages. A second, complementary approach would be to change the nature of innovation tasks, with the aim of affecting the personality traits required to successfully complete them.

\section{Literature review}

\subsection{The Five-Factor Model of personality}

This study draws on what is called Five-Factor Model of personality (Big Five). The model identifies a small number of meaningful traits in personality that display minimal overlap and provide meaningful measures for studying individual differences (McCrae and Costa 1997; Zillig, Hemenover, and Dienstbier 2002). In the model, people are assumed to have "transcontextual personality dispositions which are highly stable over time, situations, and social roles" (Sheldon et al. 1997, p. 1380). Although the adequacy of the Big Five model has been debated (e.g., Pervin 1994), an impressive body of literature has accumulated providing compelling evidence of its robustness (e.g., Conley 1985; McCrae and Costa 1985, 1987; McCrae and John 1992). The personality descriptions associated with each of the Big Five traits are as follows:

Openness to experience "characterizes someone who is intellectually curious and tends to seek new experiences and explore novel ideas" (Zhao and Seibert 2006, p. 261). Individuals with a high degree of openness to experience can be described as creative, imaginative, curious, and untraditional (George and Zhou 2001; McCrae and Costa 1985). They also tend to philosophize and appreciate art (McCrae and John 1992). In contrast, individuals low on openness to experience can be characterized as traditional, narrow in interests, unadventurous, and unanalytical (McCrae and Costa 1987).

Extraversion "describes the extent to which people are assertive, dominant, energetic, active, talkative, and enthusiastic" (Zhao and Seibert 2006, p. 260). Extraverts enjoy social 
activities and prefer being with others than being alone (LePine and Van Dyne 2001). In contrast, introverts exhibit lower social engagement, although they still value social situations involving warmth and close emotional bonds (Lucas et al. 2000).

Conscientiousness “indicates an individual's degree of organization, persistence, hard work, and motivation in the pursuit of goal accomplishment" (Zhao and Seibert 2006, p. 261). The high end of conscientiousness represents dependability, self-discipline, and achievement motivation exceeding outside expectations (e.g., Mount and Barrick 1995). Individuals with high scores on conscientiousness have a preference for planned and systematic rather than spontaneous behavior (Barrick, Mount, and Judge 2001).

Agreeableness describes an individual's interpersonal orientation, involving the tendency to prefer positive interpersonal relationships and cooperation (Digman 1990; Zhao and Seibert 2006). Agreeable individuals are associated with being conforming to social conventions, compliant, trusting, forgiving, modest, soft-hearted, and tolerant, and have been shown to engage more in cooperative, higher quality interpersonal interactions (Barrick and Mount 1991; Costa and McCrae 1992). Someone at the very low end of the dimension can be characterized as self-centered, suspicious, and hostile (Feist 1998).

Finally, neuroticism "represents the tendency to exhibit poor emotional adjustment and experience negative affects, such as anxiety, insecurity, and hostility" (Judge et. al 2002, p. 767). People who score high on neuroticism tend to be uptight and often express negative attitudes, and they have lower quality interactions with others in social situations (LePine and Van Dyne 2001). The opposite of neuroticism is emotional stability, referring to the extent an individual tends to be calm, patient, secure, and adjusted (Feist 1998; McCrae and Costa 1987).

\subsection{Links between personality types and ideation, prototyping, and diffusion}

In the literature on creativity, creative behavior generally focuses on the number and attributes of ideas generated by subjects. Openness to experience and extraversion have been shown to positively affect creative behaviors for different groups of employees (Feist 1998; Rothmann and Coetzer 2003; Sung and Choi 2009; Wolfradt and Pretz 2001). With regard to the remaining three Big Five personality traits and their implications for successful ideation, some comparisons of more creative vs. less creative scientists found that creative scientists are less conscientious (Feist 1998; George and Zhou 2001). Other studies find positive associations between creativity and conscientiousness (Feist 1998; Rothmann and Coetzer 2003). Both agreeableness (King, Walker, and Broyles 1996) and neuroticism (Rothmann and 
Coetzer 2003) have sometimes been found to correlate negatively with creative accomplishments.

Regarding links between personality traits and prototype development we identified literature that explores traits associated with being a scientist or engineer. In general, there appears to be a relationship between such career choices and introversion. Thus, in a study of Lounsbury et al. (2012), scientists had significantly lower levels of extraversion than nonscientists. A recent study by Williamson, Lounsbury, and Han (2013) found that engineers scored lower on extraversion than non-engineers. Leutner et al. (2014, p. 62) found a negative relationship between extraversion and invention-related entrepreneurship, leading them to suggest that "...more introverted individuals are more likely to be involved in developing, building, and selling designs."

With respect to disseminating the innovation, peer-to-peer diffusion of a consumerdeveloped innovation can involve activities ranging from posting illustrative material in online communities to face-to-face discussions with peers. Research related to such tasks shows that informal knowledge sharing in a work context positively depends on openness to experience, conscientiousness, and agreeableness (Matzler et al. 2008). With regard to individual sharing online specifically via Internet blogging, openness to experience and neuroticism have been shown to be important while extraversion, conscientiousness and agreeableness are of minor importance (Guadagno, Okdie, and Eno 2008). Landers and Lounsbury (2006) found extraversion, conscientiousness, and agreeableness to be negatively related to the total time an individual spends on the Internet.

Commercial diffusion of a consumer innovation would seem to involve tasks and personality traits found in successful salespeople or entrepreneurs - at least in cases when the innovator is actively trying to "sell" the innovation to firms for adoption as a product, or to customers via a startup. The literature on the personality traits of successful salespeople reports that extraversion and conscientiousness are both significant predictors of the sales and service performance of frontline employees (Barrick and Mount 1991, 1993; Liao and Chuang 2004; Thoresen et al. 2004; Vinchur et al. 1998). Conte and Gintoft (2005) show that extraversion is positively related to customer service ratings, sales performance, and overall performance. However, other studies did not find significant relationships between extraversion and sales performance (Crant 1995; Furnham and Fudge 2008).

With respect to personality traits and entrepreneurship, the Big Five have been found to significantly affect the decision of becoming an entrepreneur (Rauch and Frese 2007). A meta-analysis by Zhao and Seibert (2006) shows that, relative to managers, entrepreneurs 
score higher on openness to experience and conscientiousness and lower on agreeableness and neuroticism. No difference was found with respect to extraversion. However, several empirical studies suggest that entrepreneurship is more suitable for extraverts than introverts (Brandstätter 2011): in order to be successful, entrepreneurs need to pull together and manage a team, establish a social network, and interact with external stakeholders such as customers and investors.

In sum, we expect that traits being important at sequential stages will differ. High openness to experience might be of importance at the ideation stage, whereas low extraversion may affect the likelihood of prototyping. Whereas findings in the salespeople and entrepreneurship literature indicate that both conscientiousness and extraversion might be important to the successful accomplishment of commercial diffusion, previous research fails to give clear indications on trait predictors of peer-to-peer diffusion.

\section{Research methods}

\subsection{Sample identification and data collection}

The sample of individuals used the empirical study consists of 547 German consumers. We collected data from respondents via an online questionnaire. Because of the relatively large number of questions in the survey, the individuals invited were offered a $15 €$ Amazon gift card as an incentive to go to the site and complete the questionnaire. In order to ensure a sufficiently large number of respondents who both had and had not innovated, we followed two parallel tracks to identify survey participants.

In the first track, graduate students were engaged to contact personal acquaintances in order to collectively assemble a random set of individuals that were distributed in terms of gender, age, income, and educational degree. Each reached out to personal acquaintances to invite participation, and — to avoid community bias as well as to increase diversity — asked those contacts in turn to contact individuals in their own personal networks. Via this track, a total of 706 consumers were contacted. Of the respondents identified by the first track, 386 of the personally contacted individuals actually went to the website and completed the survey (55\% response rate).

In the second track, our goal was to increase the number of participants who had successfully prototyped and/or diffused their innovations, attributes that would otherwise have been rare in our sample. Thus, we conducted an Internet search for potential consumerinnovators. We also engaged additional graduate students to systematically search their personal networks for consumers who they knew or expected were likely to be consumer 
innovators. Based on this procedure, we identified 394 likely consumer innovators who were contacted and invited to join the study. Of the potential respondents identified via the second track, 161 went to the website and completed the questionnaire (41\% response rate).

Appendix A shows summary statistics for the final sample.

The initial section of the questionnaire asked respondents whether or not - within the last five years - they had generated an idea for a new product solution that (1) was not available in the marketplace, and (2), was intended for personal use rather than being related to their job or intended for sale. Participants who had generated an idea or prototype were then asked to describe it. If an innovator reported more than one idea, they were asked to describe the one that had reached the most advanced stage in the sequence of idea, prototype, and diffusion. If more than one prototype had been developed by a respondent, they were asked to select and describe the one that was 'most important' to them. Examples of completed prototypes described are shown in Table 1.

Table 1: Summarized examples of new products developed by consumers in the sample

\begin{tabular}{ll}
\hline Category & Example \\
\hline Medical & $\begin{array}{l}\text { I am colorblind. I developed an iPhone camera app that identifies the colors of objects in a } \\
\text { scene, and codes them for easy recognition. }\end{array}$ \\
Household & $\begin{array}{l}\text { I created a rotating and removable tray for a refrigerator to replace conventional shelves; it } \\
\text { makes it easier to store and access items. }\end{array}$ \\
I created a rain-protected gutter filled with table salt to keep snails away from my \\
vegetable garden without killing them. \\
I created a new game to make learning multiplication tables into enjoyable play for my \\
children.
\end{tabular}

\subsection{Overall data analysis strategy}

We divided respondents into four different groups of individual consumers, depicted in Figure 1, depending upon the most advanced stage of the innovation process - idea, prototype, diffusion - that they had succeeded in accomplishing. Those who reported having no new product ideas for personal use were placed into Stage 0 . Those who had one or more ideas for a novel or improved product but did not prototype any of them were placed into Stage 1, those who had developed and personally used a prototype were placed into Stage 2, and those who had also successfully diffused their innovations to others, either via a peer-topeer channel or via commercialization, were placed into Stage 3. 


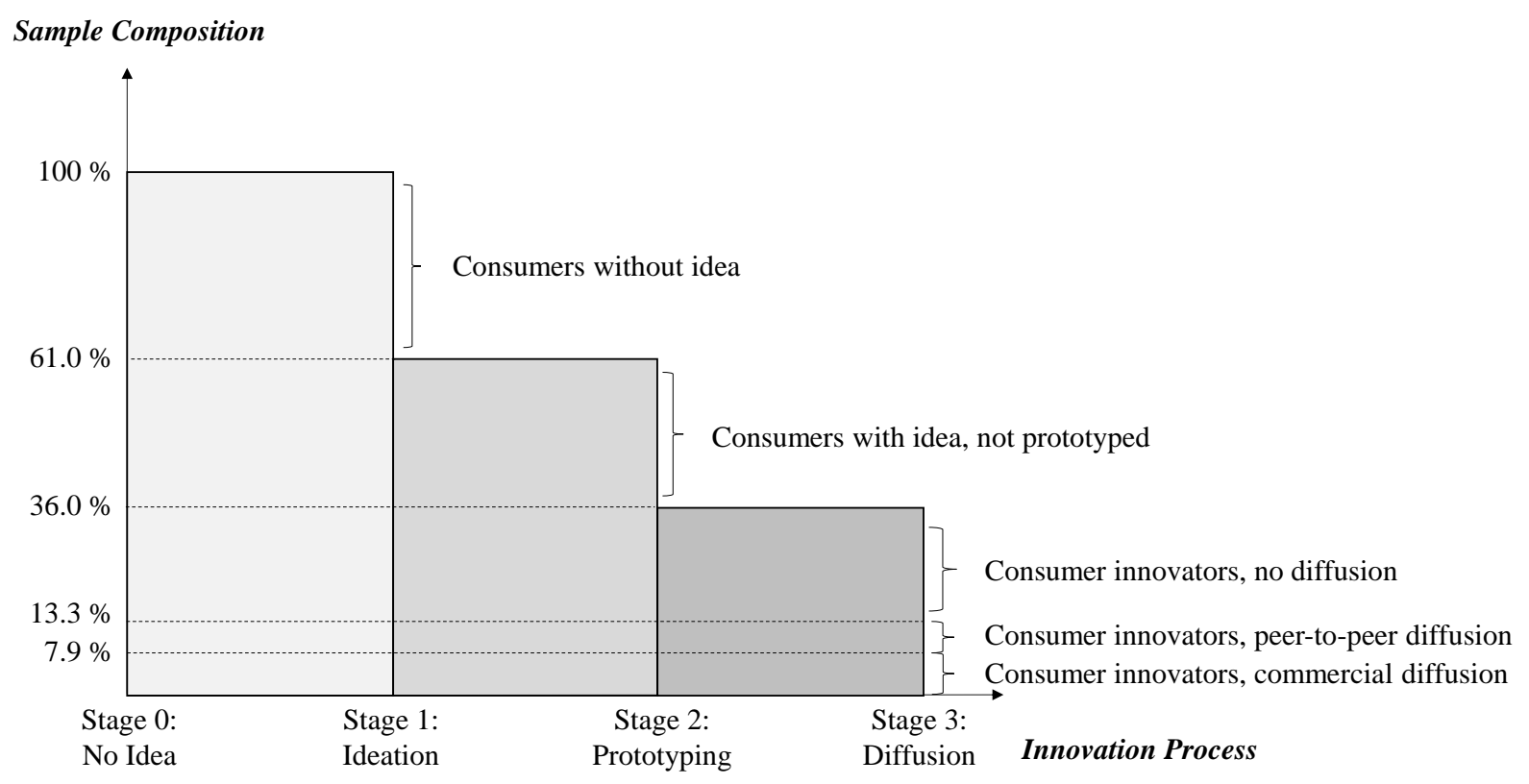

Figure 1: Data analysis strategy: comparison of individuals accomplishing vs. not accomplishing successive innovation process stages.

As can be seen in Figure 1, the number completing each successive stage was less than the number completing the prior stage, thus enabling a "success-failure" comparison at each stage. Starting at the left-hand side of Figure 1, we first explore the attributes required to successfully complete Stage 1 - having an idea. Next, for those who had an idea, we explore the impact of personality on the likelihood to develop an actual product for personal use (Stage 2). Finally, we investigate the personality attributes needed to successfully diffuse the innovation to others (Stage 3). Consistent with recent studies on diffusion of consumerdeveloped innovations (de Jong et al. 2015; von Hippel, de Jong, and Flowers 2012; von Hippel, Ogawa, and de Jong 2011), successful diffusion refers to the adoption by others, either commercially or peer-to-peer. Note that in our Stage 3 analyses, we consider the latter to be an important distinction, since individuals who diffuse their innovation peer-to-peer might well have different personality profiles than those who diffuse their innovation commercially - two very different tasks. For example, simply sharing something on the Internet for peers to examine and adopt may involve significantly different traits than would interacting with producers to convince them commercialize an innovation, or to form a company of one's own to commercialize it.

\subsection{Measurement}

Whenever possible, and based on a comprehensive literature review, we used previously validated measurements and, if necessary, adapted them. All measures are depicted 
in Appendix B. English items were translated into German by two of the authors. In addition, translations were validated by back-translation into English by a third researcher.

Discrepancies between the translations were discussed and translations that were most consistent with the original measure were identified. The resulting questionnaire was pretested.

In our study, the Big Five personality traits, openness to experience, extraversion, conscientiousness, agreeableness, and neuroticism, were measured using 50-item International Personality Item Pool representation of the domain constructs of the Five-Factor Model by Costa and McCrae's (1992), available on the Internet (Goldberg 1992, 1999; Goldberg et al. 2006, Lim and Ployhart 2006). Each subscale measures the full factor with 10 items rated from 1 (very inaccurate) to 7 (very accurate).

There are a number of factors known to have important effects on individual innovation task success in addition to personality variables. In the study we will report upon, whenever possible, these factors were used as control variables in relevant innovation process stages. First, representative national surveys of innovating and non-innovating consumers identified gender and technical background as significantly associated with the likelihood of successfully completing the ideation and prototype stages (e.g., Lüthje, Herstatt, and von Hippel 2005; Ogawa and Piller 2006; von Hippel, de Jong, and Flowers 2012). Technical background was captured by a dummy variable, indicating whether the respondent has a professional background in the field of technology, computer or natural science.

Second, the social environment, such as social ties (Perry-Smith 2006), and climate for innovation (Amabile et al. 1996; Scott and Bruce 1994) have been shown to have positive impacts in job-related settings. Thus, we used three self-developed items to capture inspiring social environment, inspired by Carmeli, Gelbard, and Reiter-Palmon (2013) and Scott and Bruce (1994). These address the extent to which an individual's social environment encourages the generation of new ideas.

Finally, we adapted a lead user measure from Franke and Shah (2003) and included the frequency of unmet needs, referring to the degree to which a respondent feels he or she has needs which are not covered by the products currently offered on the market, as a control. Summary statistics and correlations of all constructs are depicted in Table 2. As Table 2 shows, the diagonal elements representing values for Cronbach's alpha are greater than the recommended minimum .7 (Nunnally 1978), indicating a good reliability and internal consistency. Moreover, consistent with findings from related research areas (see for example Brown et al. 2002; Crant 1995; King, McKee, and Broyles 1996), the average respondent can 
be assigned to the lower end of neuroticism and to the higher end of agreeableness. Additionally, a relatively high proportion of the overall sample is male and has a technical background - probably because of the large number of consumer innovators in the sample.

Table 2: Descriptive statistics, reliabilities, and intercorrelations among measures

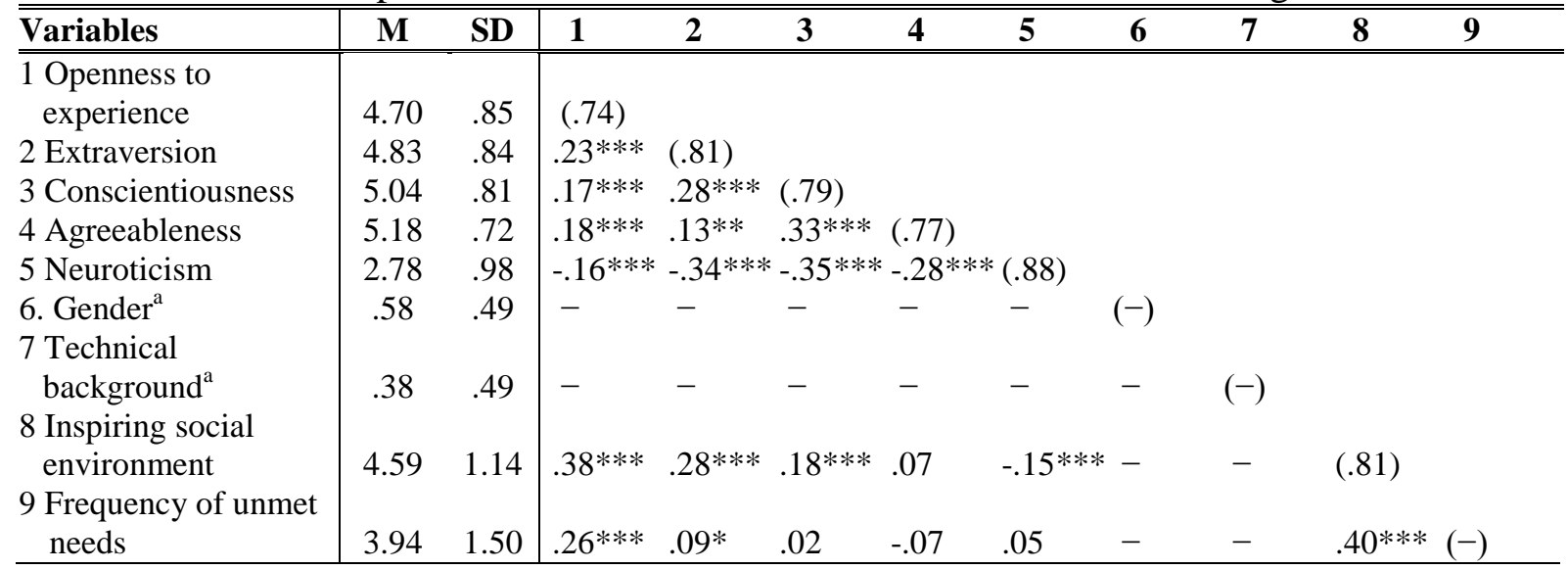

Notes: $n=547 ; \mathrm{M}=$ mean; $\mathrm{SD}=$ standard deviation; diagonal elements in parentheses are values of Cronbach's alpha; $* p<.05, * * p<.01, * * * p<.001 ; \mathrm{a}=$ dummy variable.

Overall, the average percentage of item-nonresponse was $.85 \%$. Given the shortcomings of listwise or pairwise deletion of cases with nonresponse (Roth 1994), imputation methods were used. Specifically, we used item mean scores to replace missing values of non-categorical items. To verify this procedure, we also used SPSS Statistics 22 (IBM Corp 2013) to replace missing values with five sets of reasonable values by multiple imputation in order to verify this procedure.

\subsection{Estimation and model specification}

Recall that our study was designed as a funnel of three sequential stages where an individual reaches higher stages by passing through lower ones. To cope with the sequential nature, data from 547 consumers were analyzed using sequential logit regression analysis (Buis 2011) ${ }^{1}$. For estimation of the main model, we used the Seqlogit module developed by Buis (2011) for Stata (StataCorp 2015). This model estimates the effect of a constant set of explanatory variables on a sequential outcome, that is, the probabilities of passing a set of transitions (Holm and Jæger 2011). The underlying selectivity problem involves that an individual can only progress to the next stage if the previous ones have been successfully

\footnotetext{
1 The sequential logit regression is widely used in different fields of research and also known by other names such as sequential logit model, sequential response model, continuation ratio logit, model for nested dichotomies, or Mare model (see Buis 2011).
} 
accomplished. The probability of each stage is predicted by a logit regression model, with a diminishing number of observations as the process arises.

While the estimates of the sequential logit model will demonstrate whether an effect exists, they only have limited validity in revealing and interpreting the practical significance of the findings. Thus, estimates of the unstandardized main model were used to predict changes in probabilities caused by changes in the regressors as well as for the estimation of marginal effects at the means (MEMs). We also report the amount of variance explained by the Big Five personality traits (Nagelkerke 1991). Additionally, we calculate changes in odds ratios for unit changes in the predictors which can be interpreted from the $\exp (b)$ values. We also use Cohen's $d$ as a standardized and objective measure of effect size for mean differences (Cohen 1977). Given the fact that Cohen's ranges and cut-off points for effect sizes tend to be too high in order to fit findings in applied psychology (Bosco et al. 2015), we also discuss the reported effect sizes in relation with findings from related research fields.

\subsection{Robustness tests}

Given the characteristics of the study design, unobserved factors, selection bias and choice-based sampling based on the outcome variables might raise statistical concerns (Cameron and Heckman 1998; Xie and Manski 1989). We addressed these issues by running three robustness tests.

First, to find out whether selection bias might be a problem for our model, we used the Seqlogit module to test specific scenarios about the presence of unobserved heterogeneity by running a sensitivity analysis as discussed and implemented by Buis (2007; 2011). In this approach, we introduce an unobserved standardized and normally distributed variable with varying standard deviation specified, depending on the scenario, in order to test the impact of unobserved heterogeneity on the estimated coefficients of the observed predictors.

Second, we applied a Heckman selection type of model to approximately control for non-randomly excluding observations (Heckman 1979; Holm and Jæger 2011). To consider selection in both ideation and prototyping stage, we $\left(1^{\text {st }}\right)$ estimated a probit model for Stage 1 and calculated the inverse Mills' ratio $\lambda_{1}$ for this model; $\left(2^{\text {nd }}\right)$ we estimated a probit model for Stage 2 while using $\lambda_{1}$ as an additional explanatory variable and calculated the inverse Mills' ratio $\lambda_{2}$ for this model; (3rd) we estimated a multinomial probit model for Stage 3 while using $\lambda_{2}$ as an explanatory variable. To ensure identification, each selection equation should contain at least one additional variable that is not part of the subsequent outcome equation (Holm and Jæger 2011). Therefore, we added desire for improvement and available time to innovate (see 
Appendix B) at Stage 1 and then dropped them sequentially. Moreover, to address errors resulting from the two-step estimation procedure (e.g, $\lambda_{1}$ depends on the first-stage parameter estimates and, thus, represents a statistical estimate that partly depends on the error of the former model), we used bootstrapping for the probit models of Stage 2 and Stage 3 to adjust the standard errors (Cameron and Trivedi 2010, pp. 441).

Third and finally, we addressed potential bias resulting from oversampling of individuals who successfully accomplished Stage 2 and Stage 3. Given that a random sample of the general population will not find enough cases with positive response to prototyping and diffusion, oversampling these cases by choice is a good and commonly used approach to address problems with rare data and to gain a sufficient sample size (King and Zeng 2001a). However, to provide rather robust results if the response function is misspecified, Xie and Manski (1989) suggest applying the weighted exogenous sampling maximum likelihood estimator, derived by Manski and Lerman (1977). Specifically, to examine for potential bias resulting from the sampling scheme, we applied the weighting option of the rare event logit package designed for Stata (King and Zeng 2001a, 2001b; Tomz, King, and Zeng, 1999). This package is used to maximize the weighted log-likelihood instead of the log-likelihood of the classic logit model when the sample is unbalanced or has been selected based on the outcome. Given the numbers of representative national surveys in several industrial countries ${ }^{2}$, approximate population shares are known to correct the estimates by weighting. Since those assumptions are approximations, we also increased and decreased the assumed population fractions by $3 \%$ to test whether the results differ for variation in population shares.

\section{Findings}

In brief overview, we find that personality traits associated with successful completion of each stage in the innovation process differ significantly from stage to stage. That is, individuals who rank higher in the Big Five personality trait of openness to experience are significantly more likely to have new product ideas. Being introverted and conscientious is associated with going on to realize the ideas in the form of an actual product prototype for

\footnotetext{
${ }^{2}$ With respect to the ideation stage, based on the subsample of those who have been selected without choice conditional on the outcome, we assume that about $47 \%$ of the population had an idea for a new product solution. Moreover, representative studies have shown that on average about $5 \%$ of the population innovate for personal use (de Jong et al. 2015; von Hippel, de Jong, and Flowers 2012; von Hippel, Ogawa, and de Jong 2011). Thus, we assume that about $11 \%$ of individuals with an idea prototyped. Next, these studies allow the conclusion that approximately $12 \%$ of those innovators diffuse to others, either via commercial or via peer-to-peer channels. Finally, about $5 \%$ protect their solution in order to prevent others to make commercial use of it. Based on these numbers, we calculated weights to compensate for differences in the sample fractions and the population.
} 
personal use. Those who possess high levels of conscientiousness are also more likely to commercially diffuse their innovations, but less likely to diffuse peer-to-peer.

Table 3 shows the results of the sequential logit regression analysis revealing attributes that increase the probability of stage completion. The Wald test $\chi^{2}$ statistic confirms that the model is globally significant at the $.1 \%$ level and the coefficients can be interpreted as $\log$ odds ratios. Detailed analyses of findings for each stage follow below.

Table 3: Effect of personality on consumer innovation and diffusion: Standardized sequential logit estimates

\begin{tabular}{|c|c|c|c|c|}
\hline & Stage 1 & Stage 2: & Stage 3a: & Stage 3b: \\
\hline & Ideation & Prototyping & P2P Diffusion & Commercial Diffusion \\
\hline Gender & $.39(.11)^{* * *}$ & $.62(.14)^{* * *}$ & $-.21(.27)$ & $.44(.26)$ \\
\hline Technical background & $.34(.11)^{* *}$ & $-.05(.13)$ & $.29(.21)$ & $-.27(.19)$ \\
\hline Inspiring social environment & $.49(.12)^{* * *}$ & $.14(.15)$ & $.50(.28)$ & $-.02(.21)$ \\
\hline Frequency of unmet needs & $.62(.12)^{* * *}$ & $.61(.15)^{* * *}$ & $-.10(.25)$ & $.30(.21)$ \\
\hline Openness to experience & $.35(.11)^{* *}$ & $.08(.14)$ & $.21(.24)$ & $-.09(.20)$ \\
\hline Extraversion & $.12(.11)$ & $-.51(.16)^{* *}$ & $-.28(.27)$ & $.12(.22)$ \\
\hline Conscientiousness & $-.13(.11)$ & $.31(.15)^{*}$ & $-.64(.28)^{*}$ & $.57(.28)^{*}$ \\
\hline Agreeableness & $.03(.11)$ & $-.06(.14)$ & $-.40(.25)$ & $-.28(.24)$ \\
\hline Neuroticism & $-.07(.11)$ & $-.13(.15)$ & $-.35(.32)$ & $.42(.22)$ \\
\hline Constants & $.59(.10)^{* * *}$ & $.13(.13)$ & $-1.89(.30)^{* * *}$ & $-1.53(.29) * * *$ \\
\hline
\end{tabular}

\section{Model Fit}

Wald test statistic(df) $96.36(9) * * *$

Notes: $n=547$; coefficients reported in log-odds units; robust standard errors in parentheses; the particular base categories are respondents who did not successfully complete the stage that has to be overcome. $* p<.05$, ** $p<$ $.01, * * * p<.001 ; \mathrm{df}=$ degrees of freedom

\subsection{Effect of personality on idea generation}

At the ideation stage, the Big Five traits jointly accounted for $10.5 \%$ of variance in success at ideation. Specifically, the results of the unstandardized sequential logit model show that an increase in openness to experience of one unit increases the odds of being in the group of those with an idea rather than in the group of those without an idea by $51 \%(\exp (b)=1.51)$. This was also confirmed by a significant MEM: By a one-unit increase in openness to experience, holding all other predictors at their means, the probability of successfully completing Stage 1 is increased by $9.48 \%\left(z=3.08^{* *}\right)$. The value of Cohen's $d$ as a measure of the effect size of the difference in openness to experience between consumers without an idea and consumers with an idea is $d=.56$.

With respect to the control variables, we find that respondents high on frequency of unmet needs $(\exp (b)=1.51)$ and males $(\exp (b)=2.23)$ are significantly more likely to generate ideas for a new product. In addition, the model reveals a significant and positive relation between the generation of an idea and both technical background $(\exp (b)=2.01)$ and 
inspiring social environment $(\exp (b)=1.54)$.

We also asked those with an idea who did not prototype to which extent they had had help from others on a 7-point Likert scale. Those reporting a lot of help might in principle show a weaker relationship between innovating and openness to experience-as the nonmeasured personality traits of third parties might also be relevant for ideation. However, overall, the mean value of collaboration intensity for ideation was found to be 1.61 . Thus, collaboration does not seem to be a significant issue at the ideation stage. Furthermore, the results of several $t$-tests showed no significant mean differences in terms of the Big Five between participants who had above-average collaboration intensity for ideation and those who did not.

\subsection{Effect of personality on building a prototype}

Next, we contrast attributes of those who had an idea and did not develop it into an actual product prototype for their own use with those who did actually create a usable solution. With regard to personality traits, the variance in likelihood to succeed in Stage 2 accounted by the Big Five is $8.0 \%$. First, being an introvert is significantly associated with the likelihood of successful prototyping. For each unit increase in extraversion, the odds of being in the group of consumers with a prototype decrease by $46 \%(\exp (b)=.54)$, indicating a strong inhibiting effect of extraversion with respect to successful completion of the prototyping stage. The MEM of extraversion was $-.15 \%\left(z=-3.14^{* *}\right)$. Thus, for a unitincrease in extraversion while holding the other predictors at their means, the probability of having a prototype decreases by $15 \%$. A second significant predictor of prototyping was conscientiousness $(\exp (b)=1.48)$. As reflected in the predictor's MEM, increasing conscientiousness by one increases the probability to successfully accomplish Stage 2 by $10 \%$ $\left(z=2.07^{*}\right)$. The value of Cohen's $d$ as an effect size of the extraversion difference between those who prototyped and those who did not was .30. With respect to conscientiousness, we obtained $d=.24$.

With regard to control variables, the likelihood of idea implementation again strongly depends on gender $(\exp (b)=3.53)$. Also, frequency of unmet needs contributed significantly to the prediction of building a prototype $(\exp (b)=1.51)$. Both inspiring social environment and technical background of a respondent did not significantly affect the likelihood of prototyping.

In the survey, those who successfully completed this phase were asked whether they had help from others for prototype development. Those reporting a lot of help might, in 
principle, show a weaker relationship between prototyping and personality traits. We were able to address this possibility by measuring the intensity of help from others on a 7-point scale with the bipolar poles "The new product solution did not require any help by others during its development" vs. "[...] required a lot of help by others during its development". With regard to consumers who developed a prototype, the mean value of collaboration intensity was found to be 3.42. The results of several $t$-tests showed no significant mean differences in terms of the Big Five between participants who had above-average assistance while prototyping and those who did not.

\subsection{Effect of personality on successful diffusion}

Recall that in our study we distinguish between two types of successful diffusion: peer-to-peer diffusion and commercial diffusion. We do so because we suspect that successful diffusion via each of these routes may be significantly associated with different personality traits. Regarding commercial diffusion, the Big Five explain 9.1\% in variation, which mainly stems from the significant effect of conscientiousness. Specifically, a one-unit change in conscientiousness increases the odds of commercial diffusion by $101 \%(\exp (b)=2.01)$. Regarding the underlying MEM, a unit increase in conscientiousness increases the likelihood of commercialization by $11 \%(z=2.52 *)$. The effect size of difference in conscientiousness was $d=.26$.

With respect to peer-to-peer diffusion, the Big Five explain $13.1 \%$ of the variation. In Table 3, we see that consumer innovators lower on conscientiousness were significantly more likely to diffuse peer-to-peer. Specifically, the odds of being in the group of consumers who diffused peer-to-peer instead of those who did not diffuse decrease by $55 \%(\exp (b)=0.45)$ with each unit increase of conscientiousness. The MEM for conscientiousness using the results from the unstandardized sequential logit model was $-.09\left(z=-2.57^{*}\right)$. In other words, increasing conscientiousness by one unit decreases the likelihood to diffuse peer-to-peer by 9\%. Again, we analyzed Cohen's $d$, which was found to be $d=.60$ in terms of conscientiousness at the peer-to-peer diffusion stage. To further question the reliability of this finding, we briefly explored the effect of conscientiousness on the willingness to share the innovation with peers, indicated by those who did not successfully diffuse their innovation. In line with our findings for successful peer-to-peer diffusion, we found that individuals who have not diffused yet, but who are willing to share the innovation with members of a community they belong to $(d=.49)$ or with foreign people $(d=.30)$ are characterized by lower scores of conscientiousness. 


\subsection{Results of robustness tests}

Results from the sensitivity analysis (Buis 2007, 2011) indicated that bias from selection on unobserved variables does not seem to be a substantial problem in this study. Specifically, we first added an unobserved variable whose effect varies between .2 and 2.0 (which is a very large effect, meaning that a standard deviation increase in unobserved heterogeneity leads to an increase in the odds of passing of a factor about $\exp (2.0)=7.4$ ). Even for high degrees of unobserved heterogeneity, the trend in effect of openness to experience at Stage 1, extraversion at Stage 2, and conscientiousness at Stage 3b did not change in terms of significance or sign. For high degrees of unobserved heterogeneity $(\geq 1.0)$, the conscientiousness estimates at Stage 2 and Stage 3a missed the 5\% significance level. Second, we extended this procedure as we re-estimated the model several times and let the unobserved variable be correlated with different observed predictors. Overall, from a qualitative view, most effects remained similar.

Appendix $\mathrm{C}$ provides a series of additional robustness tests. The results from the Heckman model again indicate that selection bias does not substantially influence the results. Specifically, the main predictors are qualitatively consistent with those of the main model; moreover, coefficients for $\lambda_{1}$ and $\lambda_{2}$ were not significant. However, it should be noted that the conscientiousness estimates at Stage 2 and Stage 3 a missed the 5\% significance level. Thus, these effects should be considered with certain caution.

With respect to the results calculated by rare events logit regression, personality estimates are similar to those obtained in the sequential logit model, suggesting that our results are relatively robust. Besides, varying the assumed population fractions by $+/-3 \%$ resulted in similar estimates. However, it should be noted that the $p$-value for the conscientiousness estimate at Stage 2 missed the 5\% significance level.

\subsection{Personality traits' impact on successful accomplishment of all stages in sequence}

Up to this point, we have independently considered the impacts of personality traits associated with successful accomplishment of each of the successive three major innovation process stages - ideation, prototyping, and diffusion. However, if the combination of traits an individual must possess to successfully traverse all three stages is considered, the cumulative impact of personality traits becomes quite important with respect to overall success.

By calculating predicted probabilities from the previously fit unstandardized sequential logit model, we explore what the model says about the likelihood that a type of 
person with a particular personality profile will achieve innovation success. First, consider individuals who combine the personality traits significantly associated with succeeding at completing the first two innovation stages. If we set openness to experience and conscientiousness to their $90 \%$ percentile value found in our sample and extraversion to its $10 \%$ percentile value while setting the rest of predictors to their mean values, the probability to successfully complete both Stages 1 and 2 is $52.9 \%$. In contrast, for individuals displaying low openness to experience and low conscientiousness (10\% percentile) but high extraversion ( $90 \%$ percentile), the probability to successfully complete both stages is reduced to $16.1 \%$ more than three times lower.

Next, with respect to Stage 3 success - commercial diffusion-if we set openness to experience and conscientiousness to their $90 \%$ percentiles and extraversion to its $10 \%$ percentile, the probability successfully complete Stage 1 to Stage $3 \mathrm{~b}$ is $12.4 \%$. In contrast, if we again look at individuals with low openness to experience, low conscientiousness, and high extraversion, the likelihood is reduced to $1.7 \%$ - more than 7 times lower.

Finally, if we focus on individuals who combine all personality traits significantly associated with succeeding in peer-to-peer diffusion (setting openness to experience to its $90 \%$ percentile and extraversion and conscientiousness to their $10 \%$ percentiles), the likelihood to overcome this stage is $17.5 \%$ - about 35 times higher than for the contrary personality profile $(0.5 \%)$. Given that, contrary to the peer-to-peer diffusion stage, conscientiousness has been shown to positively affect the likelihood to accomplish the prototyping stage, we next set conscientiousness to its $90 \%$ percentile value while holding openness to experience on its $90 \%$ percentile and extraversion on its $10 \%$ percentile. The resulting likelihood to successfully diffuse peer-to-peer was $4.5 \%$, which is almost four times lower than for low conscientiousness. Thus, even if high conscientiousness is supportive at the prototyping stage, it seems to be hindering for peer-to-peer-diffusion. Given the fact that personality characteristics significantly associated with successful completion of earlier stages are automatically carried into subsequent stages by the individuals who possess them, this can cause problems to successfully complete the full process.

\section{Discussion}

In this first-of-type study, we have found that different personality traits are significantly associated with success vs. failure in three important component tasks of the innovation process: having an idea, prototyping the idea, and diffusing the innovation. Recall that we found that the trait of openness to experience was significantly associated with 
successful ideation; introversion and conscientiousness were significantly associated with successful prototyping; finally, conscientiousness increased the likelihood of commercial diffusion of the innovation, but decreased the likelihood of peer-to-peer diffusion. Recall also that we used several non-personality variables as controls in our study. These variables, such as technical background and gender, have previously been found to be importantly associated with consumer innovation and they show up as important in this study as well. However, at each stage of the observed process, we found personality traits to be important additional predictors.

\subsection{Discussion of the findings relative to findings in literature}

Overall, the significant links we found for openness to experience and extraversion seem to fit findings discussed in Section 2 whereas this is only partially the case with respect to conscientiousness. Specifically, with respect to ideation, our finding that openness to experience is significantly associated with having an idea is also reflected in prior literature with respect to creative ideation and problem solving in a number of settings (see for example D'Zurilla, Maydeu-Olivares, and Gallardo-Pujol 2011; Feist 1998; George and Zhou 2001). It is likely that openness to experience encourages individuals to be creative and to come up with innovative ideas for product solutions. Interestingly, the effect size for this trait found in this study is much higher than average effect sizes found by a meta-analysis of individual personality studies in related research areas on comparisons of scientists vs. nonscientists (median $d=.11$ ) and more creative vs. less creative scientists (median $d=.31$; e.g., see Feist 1998). Perhaps, in order to come up with new product solution ideas, being intellectually curious and seeking new experiences might be even more important in consumer settings than for $R \& D$ professionals.

With respect to the prototyping stage, recall our finding that both introversion was associated with successful completion of a prototype. This is in agreement with related findings in prior literature discussed in Section 2, and the effects found in this study tend to be of similar magnitude to those found in previous related research. For example, in both engineering (Williamson, Lounsbury, and Han 2013; $d=0.39$ ) and scientific settings (Lounsbury et al. 2012, $d=0.13$ ), studies have found that R\&D performers tend to be less extraverted in comparisons to other occupational groups. Probably, introverts are more likely to prototype because they get more enjoyment out of solitary activities and prefer working in a reflective, analytic, attentive, and thoughtful manner (c.f. Feist 1998; Williamson, Lounsbury, and Han, 2013). However, given that prototype development often involves 
multiple parties and discussions with other people, a contrary result might have been likewise conceivable. Nonetheless, although individuals lower on extraversion tend to dislike spending time with large groups (Zhao and Seibert 2006), they might still appreciate close social contacts and the exchange of different views (Lucas et al. 2000), e.g., during constructive discussions with friends or selected experts for prototype development.

With respect to conscientiousness, we found that this trait significantly increases the likelihood to complete both the prototyping and the commercial diffusion stage. This is consistent with research about salespeople (e.g., Barrick and Mount 1991 report an average correlation coefficient of .09 with salespeoples' job performance; also see Liao and Chuang 2004; Vinchur et al. 1998), creative scientists (Feist 1998; medium $d=.14$ in comparison to less creative scientists), and entrepreneurs (Zhao and Seibert 2006; $d=.39$ in comparison to managers; also see Zhao, Seibert, and Lumpkin 2010), but contrary to recent studies which found that R\&D staff tends to be slightly less conscientious in comparison to other occupational groups (Lounsbury et al. 2012; Williamson, Lounsbury, and Han 2013; $d=.10$ ). As was noted above, conscientiousness is a valid predictor of job performance criteria in general and sales performance in particular. It is associated to personal characteristics such as being persistent, achievement-oriented, planful, hardworking, organized, and thorough (e.g., Barrick and Mount 1991; Thoresen et al. 2004). Possibly this general association is the explanation for the significant link between the personality trait of conscientiousness and both successful prototype completion and commercial diffusion.

Next, regarding the significant negative relationship between conscientiousness and successful peer-to-peer diffusion, we have a puzzle. On the face of it, a positive relationship might seem plausible as - based on their conforming, careful, achievement-oriented, and controlled nature - conscientious individuals usually load high on performance criteria (Barrick and Mount 1991). However, this might not be the case under conditions in which creativity, spontaneity, and thinking outside the box are important (George and Zhou 2001). In our sample, the majority of peer-to-peer diffusers posted information about their innovation on the Internet. Perhaps, to be willing to expose one's ideas to the world in this way, it might be helpful to be less conscientious, and to be untraditional, playful, and easy-going.

Finally, recall that, based largely on studies in the literature of personality traits associated with success in traditional selling activities (Barrick and Mount 1991; Conte and Gintoft 2005), we expected to find that extraversion would also be significantly associated with an individual's success at diffusing his or her innovation. This was not the case. One possible explanation could be that traditional selling activities such as socializing and face-to- 
face visits may not be characteristic of diffusion tasks undertaken by individual consumerinnovators in the Internet age - and the diffusion-related tasks that these consumers do carry out may not require high levels of extraversion.

\subsection{Implications for practice and policymaking}

Recall from Section 4.5 that we found that the effect of personality traits on successful completion of all three innovation process stages in succession was quite large. Innovators with personality profiles highly favorable to successful completion of all stages were several times more likely to successfully complete all three stages than were those with a highly unfavorable profile. Clearly, it will be important to both firms and to policymakers that all three stages are accomplished successfully.

Personality traits are relatively stable (Roberts and DelVecchio 2000), so it is unpromising to seek to change those as a means of increasing success rates. However, it seems that there are two complementary paths to improving the present situation. First, one can seek to change the nature of the task from a primarily solitary one into a collaborative effort. Second, one can change the nature of the three tasks of ideation, prototyping, and diffusion via the application of technology.

With respect to the first approach, consider that recent surveys find that from $72 \%$ to $90 \%$ of consumer innovation projects are today carried out by single individuals rather than collaboratively (Åstebro and Serrano 2015; de Jong et al. 2015; Flowers et al. 2010; Ogawa and Pongtanalert 2013; von Hippel, de Jong, and Flowers 2012). It seems possible that collaborative projects would enable partners to compensate for unfavorable personality traits by drawing in complementary personalities. In that vein, consider that, while research on established firms often highlights the importance of achieving compatibility between job applicants and the organization by striving for good person-organization fit (Arthur et al. 2006), start-up firms in effect tend to set up a team consisting of different complementary types of people when they recruit a group of individuals with expertise in a variety of categories relevant to the project (Akgün, Keskin, and Byrne 2010; Ensley and Hmieleski 2005; Vissers and Dankbaar 2002). For example, venture founders will commonly recruit an individual who has the inclination and skills to be successful at product development, and another who has the inclination and skills to be a successful marketer.

Policymaking to further support levels of collaborative innovation can include measures such as support for the development of for-profit or non-profit "maker-spaces." Here, individuals in a given area can easily find others with common interests, and also have 
access to individuals who assist and compliment in terms of personality. Cheap Internet access, along with toolkits for collaborative design, can support collaboration at a distance and ensure that all the personality traits needed to successfully complete all three innovation stages are combined.

Firms can similarly invest in support of collaborative innovation and diffusion by individual within "their" communities, as Lego does for those interested in developing and sharing novel Lego designs, and as carmakers do by offering support to groups with a special interest in modifying cars of their manufacture (Antorini, Muñiz, and Askildsen 2012). Furthermore, community providers might help consumers to find relevant partners with suitable personality profiles in order to assist within and across stages. In the absence of personality data contributed by individual participants, adequately useful personality measures might be generated by social analytics of user-generated content (Bachrach et al. 2012; Wu, Chang, and Yuan 2014).

The second, complementary approach mentioned earlier involves changing the nature of the three basic innovation tasks, with a view to affecting the personality traits required to successfully complete each. Tools to assist ideation, derived from creativity research, are commonly sold to corporations in order to help firm developers "think outside the box" and to encourage analogical thinking. Variants of these tools could be developed for individuals, and might increase their ability to develop innovation-related ideas for themselves, even if openness to experience is not one of their strong personality traits.

Similarly, prototype design and production tasks might be changed from traditional "basement workshop" activities to more easily accomplished computer-aided activities combined with clearly structured but playful frameworks, toolkits, or hardware construction kits that reduce the need to deeply reflect on idea implementation. For example, the development of inexpensive computer aided design programs combined with user-friendly user interface today may enable many laypeople to create robust designs more easily and quickly, even if they tend to be high on extraversion and low on conscientiousness. Similarly, computer-driven tools such as 3D printers increasingly enable even those who are unfamiliar with prototype fabrication methods and materials to create prototypes in simpler ways.

With respect to changing tasks associated with commercial diffusion, as was noted earlier, diffusion via face-to-face sales may be at least partly replaceable today by a diffusion process based heavily on Internet postings and Internet advertising. These different types of task may be designed to be more amenable to less conscientious individuals. For example, one might provide computerized assistance for tasks that traditionally require careful 
organization by individual participants.

Finally, with respect to changing the nature of tasks required for peer-to-peer diffusion, note that in our sample, $73 \%$ of those who successfully diffused peer-to-peer used the Internet for that purpose. Given the wide-open nature and the small amount of rules and policies on the Internet, unstructured online activities tend to appeal to less conscientious individuals (Landers and Lounsbury 2006). To increase peer-to-peer diffusion by individuals loading high on conscientiousness, community platforms and playful training programs could be designed offering structure that would make such individuals more comfortable. For example, such platforms could help conscientious individuals to enter and participate in open communities in a more 'orderly' way than the direct and unsupported immersion that is common practice today.

\subsection{Implications and suggestions for further research}

The study we reported upon here explores links between the "Big Five" personality traits and successful accomplishment of basic innovation process stages. The results show that significant relationships exist between personality traits and the successful accomplishment of basic innovation tasks by consumers. We suggest that this research can be extended to more finely-grained personality traits, and to many other applications as well.

With respect to extension of the research to other traits, recall that the Big Five personality traits are by design very broad measures of personality, especially suited to predicting global and broadly defined phenomena (Ones and Viswesvaran 1996; Schneider, Hough, and Dunnette 1996). Further research on the relationship of personality traits to innovation-related tasks could explore the impact of more fine-grained personality traits, seeking more precise associations with basic innovation activities. As a preliminary test of the potential utility of this recommendation, we found that several more precise traits did have impacts on the different forms of diffusion effort exhibited by the respondents. Based on $t$ tests, we found, for example, that those who showed their solution to others loaded significantly higher on assertiveness and self-efficacy. We also found that individuals who protect their solutions in order to prevent others from making commercial use of them are significantly more risk-taking and perfectionistic. Given the diversity and depth of the literature on traits, it seems to us that further research utilizing fine-grained personality traits are likely to provide further valuable insights on how to successfully accomplish individual innovation and diffusion tasks.

With respect to methods, given the long-standing debate on common rater effects in 
all fields of behavioral research (e.g., Podsakoff et al. 2003), future research should also consider objective measures such as number of patents or number of sold products to ensure that participants do not report on outcomes consistent with their personality. In this respect, future studies might also build on actual adoption (e.g., number of downloads), selling and profit outcomes to reveal additional policy implications. For example, recent research indicates that traits that make entrepreneurship profitable are not always the same traits that encourage individuals to start their own business (Hamilton, Papageorge, and Pande 2015). Also, future research on the impacts of personality traits on innovation success might profit from a longitudinal study design. For example, although personality traits are assumed to be relatively stable, an individual's personality profile might change over time as a result of regular engagement in ideation, prototyping, or diffusion activities. Longitudinal investigations could help to unravel any such causality and reciprocal relationships. In addition, further research might explore for differences in terms of personality patterns of consumer-innovators from other countries or cultures (McCrae and Terracciano 2005).

Finally, given the recent debate emerged on the degree to which individual and environmental or organizational characteristics should match (Muchinsky and Monahanm 1987; Schneider, Goldstein, and Smith 1995), we suggest future research to put more emphasis on the design of suitable tools and social networking services that consider the significant impact of personality on consumers' innovation and diffusion activities. For example, future studies might draw on findings by Holland (1973), indicating that organizational members are groupable into major occupation types, and individuals are more likely to be successful and satisfied if they choose for environments that match their personality traits. Overall, we very much hope that others will be inclined to join us in further studies to better understand the relationship between consumer innovator success, personality traits, and the development of appropriate approaches to increase levels of consumer innovation and diffusion. 


\section{References}

Akgün, A.E., Keskin, H., \& Byrne, J.C. (2010). Procedural Justice Climate in New Product Development Teams: Antecedents and Consequences. Journal of Product Innovation Management, 27(7), 1096-1111.

Amabile, T.M., Conti, R., Coon, H., Lazenby, J., \& Herron, M. (1996). Assessing the Work Environment for Creativity. Academy of Management Journal, 39(5), 1154-1184.

Antorini, Y.M., Muñiz, A.M., \& Askildsen, T. (2012). Collaborating with Customer Communities: Lessons from the LEGO Group. MIT Sloan Management Review, 53(3), 73-79.

Arthur, W., Bell, S.T., Villado, A.J., \& Doverspike, D. (2006). The Use of PersonOrganization Fit in Employment Decision Making: An Assessment of Its CriterionRelated Validity. Journal of Applied Psychology, 91(4), 786-801.

Åstebro, T., \& Serrano, C. (2015). Business Partners: Complementary Assets, Financing and the Commercialization of Inventions. Journal of Economics and Management Strategy, 24(2), 228-252.

Bachrach, Y., Kosinski, M., Graepel, T., Kohli, P., \& Stillwell, D. (2012). Personality and Patterns of Facebook Usage. Proceedings of the 4th Annual ACM Web Science Conference, 24-32.

Barrick, M.R., \& Mount, K.M. (1991). The Big Five Personality Dimensions and Job Performance: A Meta-Analysis. Personnel Psychology, 44(1), 1-26.

Barrick, M.R., \& Mount, K.M. (1993). Autonomy as a Moderator of the Relationships between the Big Five Personality Dimensions and Job Performance. Journal of Applied Psychology, 78(1), 111-118.

Barrick, M.R., Mount, M.K., \& Judge, T.A. (2001). Personality and Performance at the Beginning of the New Millennium: What Do We Know and Where Do We Go Next?. International Journal of Selection and Assessment, 9(1-2), 9-30.

Bosco, F.A., Aguinis, H., Singh, K., Field, J.G., \& Pierce, C.A. (2015). Correlational Effect Size Benchmarks. Journal of Applied Psychology, 100(2), 431-449.

Brandstätter, H. (2011). Personality Aspects of Entrepreneurship: A Look at Five MetaAnalyses. Personality and Individual Differences, 51(3), 222-230.

Brown, T.J., Mowen, J.C., Donavan, D.T., \& Licata, J.W. (2002). The Customer Orientation of Service Workers: Personality Trait Effects on Self- and Supervisor Performance Ratings. Journal of Marketing Research, 39(1), 110-119.

Buis, M.L. (2007). SEQLOGIT: Stata Module to Fit a Sequential Logit Model (available from http://ideas.repec.org/c/boc/bocode/s456843.html).

Buis, M.L. (2011). The Consequences of Unobserved Heterogeneity in a Sequential Logit Model. Research in Social Stratification and Mobility, 29(3), 247-262.

Cameron, S.V., \& Heckman, J.J. (1998). Life Cycle Schooling and Dynamic Selection Bias: Models and Evidence for Five Cohorts of American Males. Journal of Political Economy, 106(2), 262-333.

Cameron, A.C., \& Trivedi, P.K. (2010). Microeconometrics Using Stata (2nd edition). Texas: Stata Press.

Carmeli, A., Gelbard, R., \& Reiter-Palmon, R. (2013). Leadership, Creative Problem Solving Capacity, and Creative Performance: The Importance of Knowledge Sharing. 
Human Resource Management, 52(1), 95-121.

Cohen, J., (1977). Statistical Power Analysis for the Behavioral Sciences. Hillsdale: Erlbaum.

Conley, J.J. (1985). Longitudinal Stability of Personality Traits: A Multitrait-MultimethodMultioccasion Analysis. Journal of Personality and Social Psychology, 49(5), 12661282.

Conte, J.M., \& Gintoft, J.N. (2005). Polychronicity, Big Five Personality Dimensions, and Sales Performance. Human Performance 18(4), 427-444.

Costa, P.T., \& McCrae, R.R. (1992). Revised NEO Personality Inventory (NEO-PI-R) and NEO Five-Factor Inventory (NEO-FFI) professional manual. Odessa: Psychological Assessment Resources.

Crant, J.M. (1995). The Proactive Personality Scale and Objective Job Performance among Real Estate Agents. Journal of Applied Psychology, 80(4), 532-537.

de Jong, J.P.J. (2013). User Innovation by Canadian Consumers, Analysis of a Sample of 2,021 Respondents, Commisioned by Industry Canada (unpublished).

de Jong, J.P., von Hippel, E., Gault, F., Kuusisto, J., \& Raasch, C. (2015). Market Failure in the Diffusion of Consumer-developed Innovations: Patterns in Finland. Research Policy, 44(10), 1856-1865.

Digman, J.M. (1990). Personality Structure: Emergence of the Five-Factor Model. Annual Review of Psychology, 41(1), 417-440.

D’Zurilla, T.J., Maydeu-Olivares, A., \& Gallardo-Pujol, D. (2011). Predicting Social Problem Solving Using Personality Traits. Personality and Individual Differences, 50(2), 142 147.

Ensley, M.D., \& Hmieleski, K.M. (2005). A Comparative Study of New Venture Top Management Team Composition, Dynamics and Performance Between Universitybased and Independent Start-ups. Research Policy, 34(7), 1091-1105.

Feist, G.J. (1998). A Meta-Analysis of Personality in Scientific and Artistic Creativity. Personality and Social Psychology Review, 2(4), 290-309.

Flowers, S., von Hippel, E., de Jong, J., \& Sinozic, T. (2010). Measuring User Innovation in the UK: The Importance of Product Creation by Users. London: NESTA.

Franke, N., \& Shah, S. (2003). How Communities Support Innovative Activities: An Exploration of Assistance and Sharing Among End-Users. Research Policy, 32(1), 157-178.

Furnham, A., \& Fudge, C. (2008). The Five Factor Model of Personality and Sales Performance. Journal of Individual Differences, 29(1), 11-16.

Gambardella, A., Raasch, C., \& von Hippel, E. (2015). The User Innovation Paradigm: Impacts on Markets and Welfare. Working Paper (available at http://ssrn.com/abstract=2079763).

George, J.M., \& Zhou, J. (2001). When Openness to Experience and Conscientiousness are Related to Creative Behavior: An Interactional Approach. Journal of Applied Psychology, 86(3), 513-524.

Goldberg, L.R. (1992). The Development of Markers for the Big-Five Factor Structure. Psychological Assessment, 4(1), 26-42.

Goldberg, L.R. (1999). A Broad-Bandwidth, Public-Domain, Personality Inventory 
Measuring the Lower-Level Facets of Several Five-Factor Models, in: Mervielde, I., Deary, I., De Fruyt, F., Ostendorf, F. (Eds), Personality Psychology in Europe. Tilburg University Press, Tilburg, 7-28.

Goldberg, L.R., Johnson, J.A., Eber, H.W., Hogan, R., Ashton, M.C., Cloninger, C.R., \& Gough, H.G. (2006). The International Personality Item Pool and the Future of PublicDomain Personality Measures. Journal of Research in Personality, 40(1), 84-96.

Guadagno, R.E., Okdie, B.M., \& Eno, C.A. (2008). Who Blogs? Personality Predictors of Blogging. Computers in Human Behavior, 24(5), 1993-2004.

Hamilton, B.H., Papageorge, N.W., \& Pande, N. (2015). The Right Stuff? Personality and Entrepreneurship. Working Paper (available at https://nicholaswpapageorge.files.wordpress.com/2011/06/personality1.pdf).

Heckman, J.J., 1979. Sample Selection Bias as a Specification Error. Econometrica, 47(1), 153-161.

Holland, J. L. (1997). Making Vocational Choices: A Theory of Vocational Personalities and Work Environments (3rd edition). Odessa: Psychological Assessment Resources.

Holm, A., \& Jæger, M. M., 2011. Dealing with Selection Bias in Educational Transition Models: The Bivariate Probit Selection Model. Research in Social Stratification and Mobility, 29(3), 311-322.

IBM Corp (2013). IBM SPSS Statistics for Windows, Version 22.0. Armonk: IBM Corp.

Judge, T.A., Bono, J.E., Ilies, R., \& Gerhardt, M.W. (2002). Personality and Leadership: A Qualitative and Quantitative Review. Journal of Applied Psychology, 87(4), 765-781.

Kim, Y. (2015). Consumer User Innovation in Korea: An International Comparison and Policy Implications. Asian Journal of Technology Innovation, 23(1), 69-86.

King, L.A., Walker, L.M., \& Broyles, S.J. (1996). Creativity and the Five-Factor Model. Journal of Research in Personality, 30(2), 189-203.

King, G., \& Zeng, L. (2001a). Logistic Regression in Rare Events Data. Political Analysis, 9(2), 137-163.

King, G., \& Zeng, L. (2001b). Explaining Rare Events in International Relations. International Organization, 55(3), 693-715.

Landers, R.N., \& Lounsbury, J.W. (2006). An Investigation of Big Five and Narrow Personality Traits in Relation to Internet Usage. Computers in Human Behavior, 22(2), 283-293.

LePine, J.A., Van Dyne, L., 2001. Voice and Cooperative Behavior as Contrasting Forms of Contextual Performance: Evidence of Differential Relationships with Big Five Personality Characteristics and Cognitive Ability. Journal of Applied Psychology, 86(2), 326-336.

Leutner, F., Ahmetoglu, G., Akhtar, R., \& Chamorro-Premuzic, T. (2014). The Relationship between the Entrepreneurial Personality and the Big Five Personality Traits. Personality and Individual Differences, 63(2014), 58-63.

Liao, H., \& Chuang, A. (2004). A Multilevel Investigation of Factors Influencing Employee Service Performance and Customer Outcomes. Academy of Management Journal, 47(1), 41-58.

Lim, B.C., \& Ployhart, R.E. (2006). Assessing the Convergent and Discriminant Validity of 
Goldberg's International Personality Item Pool: A Multitrait-Multimethod Examination. Organizational Research Methods, 9(1), 29-54.

Lounsbury, J.W., Foster, N., Patel, H., Carmody, P., Gibson, L.W., \& Stairs, D.R. (2012). An Investigation of the Personality Traits of Scientists versus Nonscientists and their Relationship with Career Satisfaction. R\&D Management, 42(1), 47-59.

Lucas, R.E., Diener, E., Grob, A., Suh, E.M., \& Shao, L. (2000). Cross-cultural Evidence for the Fundamental Features of Extraversion. Journal of Personality and Social Psychology, 79(3), 452-468.

Lüthje, C., Herstatt, C., \& von Hippel, E. (2005). User-innovators and "Local" Information: The Case of Mountain Biking. Research Policy, 34(6), 951-965.

Manski, C.F., \& Lerman, S.R. (1977). The Estimation of Choice Probabilities from Choice Based Samples. Econometrica, 45(8), 1977-1988.

Matzler, K., Renzl, B., Müller, J., Herting, S., \& Mooradian, T.A. (2008). Personality Traits and Knowledge Sharing. Journal of Economic Psychology, 29(3), 301-313.

McCrae, R.R., \& Costa, P.T. (1985). Updating Norman’s „Adequate Taxonomy“: Intelligence and Personality Dimensions in Natural Language and in Questionnaires. Journal of Personality \& Social Psychology, 49(3), 710-721.

McCrae, R.R., \& Costa, P.T. (1987). Validation of the Five-Factor Model of Personality across Instruments and Observers. Journal of Personality \& Social Psychology, 52(1), 81-90.

McCrae, R.R., \& Costa, P.T. (1997). Personality Trait Structure as a Human Universal. American Psychologist, 52(5), 509-516.

McCrae, R.R., \& John, O.P. (1992). An Introduction to the Five-Factor Model and its Applications. Journal of Personality, 60(2), 175-215.

McCrae, R.R., \& Terracciano, A. (2005). Personality Profiles of Cultures: Aggregate Personality Traits. Journal of Personality and Social Psychology, 89(3), 407-425.

Mount, M.K., \& Barrick, M.R. (1995). The Big Five Personality Dimensions: Implications for Research and Practice in Human Resources Management. Research in Personnel and Human Resources Management, 13(3), 153-200.

Muchinsky, P.M., \& Monahan, C.J. (1987). What is Person-Environment Congruence? Supplementary versus Complementary Models of Fit. Journal of Vocational Behavior, 31(3), 268-277.

Nagelkerke, N.J.D. (1991). A Note on a General Definition of the Coefficient of Determination. Biometrika, 78(3), 691-692.

Nunnally, J.C. (1978). Psychometric Theory (2nd edition). New York: McGraw-Hill.

Ogawa, S., \& Piller, F.T. (2006). Reducing the Risks of New Product Development. Sloan Management Review, 47(1), 189-204.

Ogawa, S., \& Pongtanalert, K. (2013). Exploring Characteristics and Motives of Consumer Innovators: Community Innovators vs. Independent Innovators. Research Technology Management, 56(3), 41-48.

Ones, D.S., \& Viswesvaran, C. (1996). Bandwidth-fidelity Dilemma in Personality Measurement for Personnel Selection. Journal of Organizational Behavior, 17(6), 609626. 
Perry-Smith, J.E. (2006). Social yet Creative: The Role of Social Relationships in Facilitating Individual Creativity. Academy of Management Journal, 49(1), 85-101.

Pervin, L.A. (1994). A Critical Analysis of Current Trait Theory. Psychological Inquiry, 5(2), 103-113.

Podsakoff, P.M., MacKenzie, S.B., Lee, J.Y., \& Podsakoff, N.P. (2003). Common Method Biases in Behavioral Research: A Critical Review of the Literature and Recommended Remedies. Journal of Applied Psychology, 88(5), 879-903.

Rauch, A., \& Frese, M. (2007). Let's Put the Person Back into Entrepreneurship Research: A Meta-Analysis on the Relationship Between Business Owners' Personality Traits, Business Creation, and Success. European Journal of Work and Organizational Psychology, 16(4), 353-385.

Roberts, B.W., \& DelVecchio, W.F. (2000). The Rank-order Consistency of Personality Traits from Childhood to Old Age: A Quantitative Review of Longitudinal Studies. Psychological Bulletin, 126(1), 3-25.

Roth, P.L. (1994). Missing Data: A Conceptual Review for Applied Psychologists. Personnel Psychology, 47(3), 537-560.

Rothmann, S., \& Coetzer, E.P. (2003). The Big Five Personality Dimensions and Job Performance. South African Journal of Industrial Psychology, 29(1), 68-74.

Schneider, B., Goldstein, H.W., \& Smith, D.B. (1995). The ASA Framework: An Update. Personnel Psychology, 48(4), 747-773.

Schneider, R.J., Hough, L.M., \& Dunnette, M.D. (1996). Broadsided by Broad Traits: How to Sink Science in Five Dimensions or Less. Journal of Organizational Behavior, 17(6), 639-655.

Scott, S.G., \& Bruce, R.A. (1994). Determinants of Innovative Behavior: A Path Model of Individual Innovation in the Workplace. Academy of Management Journal, 37(3), 580-607.

Sheldon, K.M., Ryan, R.M., Rawsthorne, L.J., \& Ilardi, B. (1997). Trait Self and True Self: Cross-role Variation in the Big-Five Personality Traits and its Relations with Psychological Authenticity and Subjective Well-being. Journal of Personality and Social Psychology, 73(6), 1380-1393.

StataCorp (2015). Stata: Release 14. Statistical Software. College Station: StataCorp LP.

Stock, R.M., Oliveira, P., \& Hippel, E. (2015). Impacts of Hedonic and Utilitarian User Motives on the Innovativeness of User-Developed Solutions. Journal of Product Innovation Management, 32(3), 389-403.

Sung, S.Y., \& Choi, J.N. (2009). Do Big Five Personality Factors Affect Individual Creativity? The Moderating Role of Extrinsic Motivation. Social Behavior and Personality, 37(7), 941-956.

Thoresen, C.J., Bradley, J.C., Bliese, P.D., \& Thoresen, J.D. (2004). The Big Five Personality Traits and Individual Job Performance Growth Trajectories in Maintenance and Transitional Job Stages. Journal of Applied Psychology, 89(5), 835-853.

Tomz, M., King, G., \& Zeng, L. (1999). RELOGIT: Rare Events Logistic Regression, Version 1.1 Cambridge, MA: Harvard University (available at http://gking.harvard.edu/).

Vinchur, A.J., Schippmann, J.S., Switzer, F.S., \& Roth, P.L. (1998). A Meta-Analytic Review 
of Predictors of Job Performance for Salespeople. Journal of Applied Psychology, 83(4), 586-597.

Vissers, G., \& Dankbaar, B. (2002). Creativity in Multidisciplinary New Product Development Teams. Creativity and Innovation Management, 11(1), 31-42.

von Hippel, E., de Jong, J.P.J., \& Flowers, S. (2012). Comparing Business and Household Sector Innovation in Consumer Products: Findings from a Representative Study in the UK. Management Science, 58(9), 1669-1681.

von Hippel, E., Ogawa, S., \& de Jong, J.P.J. (2011). The Age of the Consumer-Innovator. MIT Sloan Management Review, 53(1), 27-35.

Williamson, J.M., Lounsbury, J.W., \& Han, L.D. (2013). Key Personality Traits of Engineers for Innovation and Technology Development. Journal of Engineering and Technology Management, 30(2), 157-168.

Wolfradt, U., \& Pretz, J. E. (2001). Individual Differences in Creativity: Personality, Story Writing, and Hobbies. European Journal of Personality, 15(4), 297-310.

Wu, Y.C.J., Chang, W.H., \& Yuan, C.H. (2014). Do Facebook Profile Pictures Reflect User's Personality?. Computers in Human Behavior, 51(2015), 880-889.

Xie, Y., \& Manski, C. F. (1989). The Logit Model and Response-Based Samples. Sociological Methods \& Research, 17(3), 283-302.

Zhao, H., \& Seibert, S.E. (2006). The Big Five Personality Dimensions and Entrepreneurial Status: A Meta-Analytical Review. Journal of Applied Psychology, 91(2), 259-271.

Zhao, H., Seibert, S.E., \& Lumpkin, G.T. (2010). The Relationship of Personality to Entrepreneurial Intentions and Performance: A Meta-Analytic Review. Journal of Management, 36(2), 381-404.

Zillig, L.M.P., Hemenover, S.H., \& Dienstbier, R.A. (2002). What Do We Assess When We Assess a Big 5 Trait? A Content Analysis of the Affective, Behavioral, and Cognitive Processes Represented in Big 5 Personality Inventories. Personality and Social Psychology Bulletin, 28(6), 847-858. 
Appendix A: Sample demographics

\begin{tabular}{|c|c|c|c|c|}
\hline & $\begin{array}{c}\text { Consumers } \\
\text { without idea } \\
(n=214)\end{array}$ & $\begin{array}{c}\text { Consumers with } \\
\text { idea, not } \\
\text { prototyped } \\
(n=136)\end{array}$ & $\begin{array}{c}\text { Consumers with } \\
\text { idea, prototyped, } \\
\text { not diffused } \\
(n=124)\end{array}$ & $\begin{array}{c}\text { Consumers with } \\
\text { idea, prototyped, } \\
\text { diffused } \\
(n=73)\end{array}$ \\
\hline Mean Age [years] & 37.4 & 32.0 & 42.9 & 44.1 \\
\hline \multicolumn{5}{|l|}{ Age classes [\%] } \\
\hline$\leq 24$ years & 23.8 & 27.9 & 12.1 & 6.9 \\
\hline 25-34 years & 30.4 & 44.9 & 24.2 & 17.8 \\
\hline $35-44$ years & 11.7 & 11.8 & 12.1 & 23.3 \\
\hline $45-54$ years & 18.7 & 6.6 & 29.0 & 31.5 \\
\hline $55-64$ years & 8.9 & 5.1 & 12.9 & 13.7 \\
\hline$\geq 65$ years & 6.5 & 3.7 & 9.7 & 6.9 \\
\hline \multicolumn{5}{|l|}{$\begin{array}{l}\text { Highest educational } \\
\text { background [\%] }\end{array}$} \\
\hline $\begin{array}{l}\text { lower than High } \\
\text { School degree }\end{array}$ & 34.6 & 20.3 & 23.5 & 27.1 \\
\hline High School degree & 25.6 & 33.8 & 29.4 & 17.1 \\
\hline $\begin{array}{l}\text { University } \\
\text { degree/College degree }\end{array}$ & 36.5 & 44.4 & 44.5 & 52.9 \\
\hline Ph.D. & 3.3 & 1.5 & 2.5 & 2.9 \\
\hline Professional & & & & \\
\hline \\
\hline $\begin{array}{l}\text { Science/Natural } \\
\text { Science/Technology }\end{array}$ & 27.1 & 39.7 & 49.2 & 48.0 \\
\hline $\begin{array}{l}\text { Construction/ } \\
\text { Manufacturing/Crafts }\end{array}$ & 7.0 & 8.1 & 15.3 & 12.3 \\
\hline Sales/Services/Trade & 29.4 & 15.4 & 11.3 & 8.2 \\
\hline Administration/Justice & 8.9 & 6.6 & 4.8 & 0.0 \\
\hline Health/Social/Teaching & 12.6 & 16.2 & 7.3 & 6.9 \\
\hline Arts/Culture/Media & 5.1 & 6.6 & 1.6 & 8.2 \\
\hline Other & 9.8 & 7.4 & 10.5 & 16.4 \\
\hline \multicolumn{5}{|l|}{ Gender $[\%]$} \\
\hline male & 43.0 & 49.3 & 23.4 & 17.8 \\
\hline female & 57.0 & 50.7 & 76.6 & 82.2 \\
\hline $\begin{array}{l}\text { Average Working } \\
\text { Experience [years] }\end{array}$ & 14.3 & 9.6 & 19.8 & 20.7 \\
\hline \multicolumn{5}{|l|}{$\begin{array}{l}\text { Available monthly } \\
\text { income [\$] }\end{array}$} \\
\hline$<750$ & 24.4 & 22.8 & 19.5 & 6.9 \\
\hline $751-1500$ & 18.3 & 26.5 & 14.6 & 23.6 \\
\hline $1501-2000$ & 11.3 & 16.2 & 13.0 & 6.9 \\
\hline $2001-3000$ & 19.3 & 16.9 & 20.3 & 18.1 \\
\hline $3001-5000$ & 16.9 & 10.3 & 18.7 & 19.4 \\
\hline $5001-8000$ & 7.0 & 3.7 & 10.6 & 19.4 \\
\hline$>8000$ & 2.8 & 3.7 & 3.3 & 5.6 \\
\hline
\end{tabular}




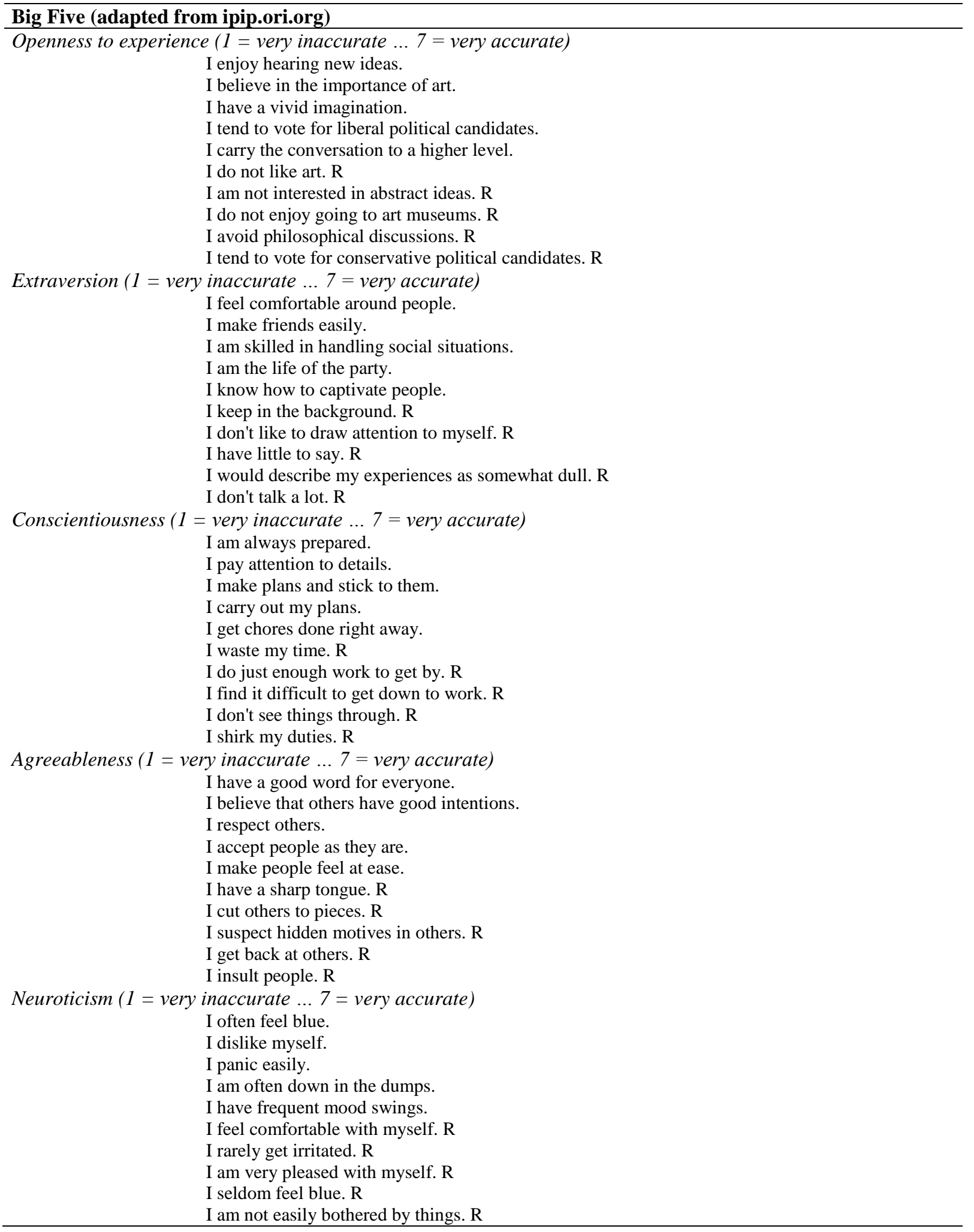




\section{Appendix B: Measures (continued)}

\section{Control variables}

Gender $(0=$ female $; 1=$ male $)$

Technical background $(0=$ no, $1=$ yes $)$

Dummy variable for the respondent's sex.

Dummy variable for those with a professional background in technology, computer or natural science.

Inspiring social environment (inspired by Carmeli, Gelbard, and Reiter-Palmon (2013) and Scott and Bruce (1994); $1=$ totally disagree $\ldots 7=$ totally agree)

I have access to people who encourage to come up with new ideas.

I have access to people who would listen to my ideas.

My ability to function creatively is respected by people I care about.

I interact with my family and friends to discuss suggestions and ideas.

Frequency of unmet needs (adapted from Franke and Shah (2003); $1=$ totally disagree ... 7 = totally agree)

I frequently have needs which are not covered by the products currently offered on the market.

Available time to innovate (inspired by Scott and Bruce (1994); $1=$ totally disagree ... $7=$ totally agree)

I have sufficient time to generate new ideas if I like to.

My life situation allows me to be open and responsive to change.

In my leisure, there is adequate time available to pursue creative ideas.

Desire for improvement (self-developed; $1=$ totally disagree $\ldots .7=$ totally agree)

Regarding my hobbies and/or my home environment, there are things I would like to improve.

Dependent variables
Idea generation $(0=n o ; 1=$ yes $)$

Prototyping $(0=$ no $; 1=$ yes $)$

Consumer generated at least one idea for a new product solution or a modification of existing product solutions within the past five years which would be useful for own use or the use of close relatives.

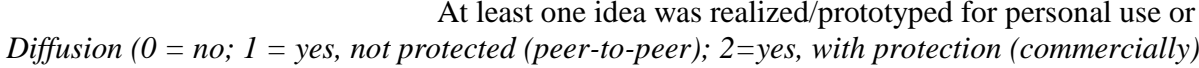

Consumer is aware of actual adoption by other consumers and/or firms (If the prototype has been developed for a close relative or friend, this person was not meant here): a) without or b) with protection of the product solution in order to prevent others making commercial use of it (e.g., patenting).

Notes: $\mathrm{R}=$ reversed coded item. 
Appendix C: Robustness checks

\begin{tabular}{|c|c|c|c|c|c|c|c|c|}
\hline & \multicolumn{4}{|c|}{ Heckman correction } & \multicolumn{4}{|c|}{ Rare events logit regression (Relogit) } \\
\hline & $\begin{array}{c}\text { Probit } \\
\text { regression } \\
\text { Stage 1: }\end{array}$ & $\begin{array}{c}\text { Probit } \\
\text { regression } \\
\text { Stage 2: }\end{array}$ & $\begin{array}{r}\text { Mul } \\
\text { regress }\end{array}$ & $\begin{array}{l}\text { al probit } \\
\text { ge } 3 a \text { and } b \text { : }\end{array}$ & $\begin{array}{l}\text { Relogit } \\
\text { Stage } 1\end{array}$ & $\begin{array}{l}\text { Relogit } \\
\text { Stage 2: }\end{array}$ & $\begin{array}{c}\text { Relogit } \\
\text { Stage 3a: }\end{array}$ & $\begin{array}{c}\text { Relogit } \\
\text { Stage 3b: }\end{array}$ \\
\hline & $\underline{\text { Ideation }}$ & Prototyping & $\underline{\text { Diffusion }}$ & $\frac{\text { Commercial }}{\underline{\text { Diffusion }}}$ & $\underline{\text { Ideation }}$ & Prototyping & $\underline{\text { P2P Diffusion }}$ & $\frac{\text { Commercial }}{\underline{\text { Diffusion }}}$ \\
\hline \multicolumn{9}{|l|}{ Control Variables } \\
\hline Gender & $.21(.06)^{* *}$ & $.48(.13)^{* * *}$ & $.12(.42)$ & $.90(.42)^{*}$ & $.40(.10)^{* * *}$ & $.60(.14)^{* * *}$ & $-.19(.24)$ & $.36(.27)$ \\
\hline Technical background & $.20(.06)^{* *}$ & $.08(.12)$ & $.24(.20)$ & $-.22(.16)$ & $.34(.10)^{* *}$ & $-.05(.13)$ & $.19(.21)$ & $-.24(.19)$ \\
\hline $\begin{array}{l}\text { Inspiring social } \\
\text { environment }\end{array}$ & $.23(.08)^{* *}$ & $.18(.16)$ & $.46(.26)$ & $.13(.21)$ & $.50(.12)^{* * *}$ & $.19(.15)$ & $.40(.27)$ & $.01(.21)$ \\
\hline $\begin{array}{l}\text { Frequency of unmet } \\
\text { needs }\end{array}$ & $.32(.07)^{* * *}$ & $.55(.16)^{* * *}$ & $.18(.44)$ & $.72(.40)$ & $.62(.11)^{* * *}$ & $.69(.16)^{* * * *}$ & $-.12(.24)$ & $.26(.22)$ \\
\hline \multicolumn{9}{|l|}{ Big Five } \\
\hline $\begin{array}{l}\text { Openness to } \\
\text { experience }\end{array}$ & $.18(.07)^{* *}$ & $.12(.12)$ & $.20(.21)$ & $-.01(.19)$ & $.34(.11)^{* *}$ & $.01(.14)$ & $.18(.23)$ & $-.05(.19)$ \\
\hline Extraversion & $.08(.07)$ & $-.25(.09) * *$ & $-.38(.29)$ & $-.25(.30)$ & $.11(.11)$ & $-.38(.15)^{*}$ & $-.29(.25)$ & $.10(.20)$ \\
\hline Conscientiousness & $-.07(.07)$ & $.16(.10)$ & $-.31(.29)$ & $.64(.31)^{*}$ & $-.10(.11)$ & $.22(.14)$ & $-.59(.27)^{*}$ & $.58(.29)^{*}$ \\
\hline Agreeableness & $.02(.07)$ & $-.01(.09)$ & $-.34(.23)$ & $-.25(.21)$ & $.05(.11)$ & $-.04(.14)$ & $-.31(.26)$ & $-.28(.29)$ \\
\hline Neuroticism & $-.04(.07)$ & $-.06(.10)$ & $-.26(.27)$ & $.26(.18)$ & $-.04(.11)$ & $-.06(.14)$ & $-.31(.33)$ & $.38(.23)$ \\
\hline $\begin{array}{l}\text { Available time to } \\
\text { innovate }\end{array}$ & $.09(.07)$ & $.21(.09)^{*}$ & & & & & & \\
\hline $\begin{array}{l}\text { Desire for } \\
\text { improvement }\end{array}$ & $.11(.07)$ & & & & & & & \\
\hline$\lambda_{1}$ & & $1.05(.87)$ & & & & & & \\
\hline$\lambda_{2}$ & & & $1.26(1.72)$ & $2.56(1.87)$ & & & & \\
\hline Constants & $.36(.06)^{* * *}$ & $-.59(.56)$ & $-2.46(1.39)$ & $-3.20(1.45)^{*}$ & $.03(.10)$ & $-2.36(.14)^{* * *}$ & $-2.83(.28)^{* * *}$ & $-3.30(.30) * * *$ \\
\hline$n$ & 547 & 333 & & & 547 & 333 & 154 & 167 \\
\hline
\end{tabular}

Notes: standard errors in parentheses; bootstrap standard errors for Heckman corrections in Stage 2 and 3; robust standard errors for rare events logit regression; the particular base categories are respondents who did not successfully complete the stage to be overcome. $* p<.05, * * p<.01, * * * p<.001$; df $=$ degrees of freedom 
